\title{
Torquoselective mechanochemical activation of the Staudinger reaction to form $\beta$-lactams
}

\author{
Dominik Marx, ${ }^{1}$ and María Isabel Menéndez ${ }^{2 *}$
}

${ }^{1}$ Lehrstuhl für Theoretische Chemie, Ruhr-Universität Bochum, 44780 Bochum, Germany. E-mail: dominik.marx@rub.de

2,* Departamento de Química Física y Analítica, Facultad de Química Universidad de Oviedo, C/ Julián Clavería 8, 33006 Oviedo, Spain 
TOC Graphic

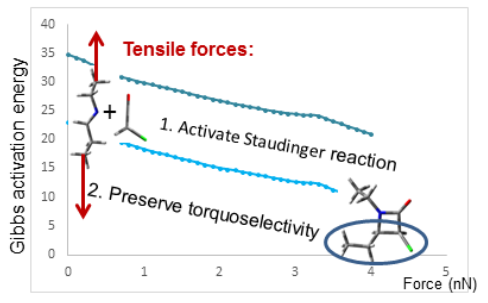

\section{ABSTRACT}

The Staudinger reaction yielding $\beta$-lactam rings via $[2+2]$ cycloaddition is a torquoselective reaction where the stereochemistry of the product can be steered by suitable substituents. Although the mechanochemical ring-opening of $\beta$-lactams has been investigated recently, the force-assisted synthesis of this important functional four-ring motif remains unexplored. As it will be computationally demonstrated, mechanochemical activation greatly reduces the barrier of the rate limiting ring-closure step while, at the same time, preserves its torquoselectivity. This finding strongly suggests that strained four-membered rings can be readily incorporated in chain molecules using sonication techniques that greatly enhance reactivity while conserving selectivity.

\section{KEYWORDS}

Density Function Calculations, Mechanochemistry, Staudinger reaction, Stereoselectivity 
The broad relevance of the $\beta$-lactam ring, azetidin-2-one, stems primarily from its scaffold role in many antibacterial chemicals ${ }^{1,2}$ and also from its use in synthetic organic chemistry. ${ }^{3}$ These significant applications triggered the development of convenient chemical methods for the construction of the ring, ${ }^{4}$ although innovations coming from new approaches are still needed. ${ }^{5,6}$ In this sense, theoretical predictions on the effect of mechanical forces acting on one reactant are useful, as it will be soon demonstrated.

The first synthesis of the $\beta$-lactam ring was reported by Staudinger as the cycloaddition reaction of ketenes and imines, and nowadays remains as one of the most general and useful methods for generating this motif and its derivatives. ${ }^{7-8}$ In solution, the reaction takes place in two steps, the nucleophilic addition of the imine nitrogen to the ketene to form a zwitterionic intermediate, followed by the usually rate limiting closure of the ring ${ }^{9}$ (see schematic mechanistic pathways and atom numbering in Scheme 1).

Scheme 1. Exo (a) and endo (b) mechanistic pathways for the Staudinger reaction involving chloro- and CHO-ketene, respectively.

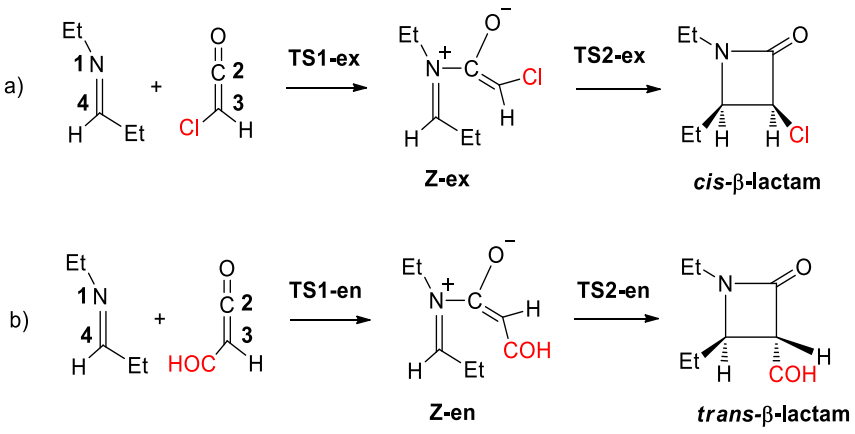

The stereochemistry of the final product is a particularly relevant issue. Starting with asymmetrically substituted imines and ketenes, two chiral centers are generated and their configuration affects the biological activity of $\beta$-lactam derivatives. ${ }^{10}$ The first nucleophilic attack takes place through the less hindered side of the ketene, but this is mostly a low-energy reversible process ${ }^{11}$ whereas torquoselectivity operates in the second 
rate-limiting irreversible step, that is, the electronic character of the substituents at $\mathrm{C} 3$ and C4 determines if clockwise or counter-clockwise rotation is preferred. ${ }^{12-13} \mathrm{~A} \pi$-electrondonating substituent, such as chlorine, tends to place itself in the rate-limiting step on the outside to minimize the repulsive filled-filled orbital interactions between the donor orbital and the $\sigma$ orbital of the partially formed $\sigma$ bond. In stark contrast, $\pi$-electronaccepting groups (those with low-lying empty orbitals), such as $\mathrm{CHO}$, feature much reduced outward preference or even prefer the inside arrangement to maximize favorable overlap of the empty $\pi^{*}$ orbital of the substituent and the HOMO of the partially formed bond. Alternative explanations for the stereochemistry of the products have been reported for some systems where the intermediate zwitterion ${ }^{14,15}$ or the imine itself ${ }^{16-17}$ can readily isomerize, but the stereochemistry of most Staudinger reaction products can be rationalized on the basis of the steric and electronic arguments above explained. ${ }^{18}$

Despite a plethora of synthetic proposals to enhance reactivity while keeping selectivity, ${ }^{5}$ including photochemical and microwave promotion, ${ }^{14}$ mechanochemical activation ${ }^{19,20}$ has not yet been considered in the synthesis of $\beta$-lactams to our best knowledge. Yet, some experimental work reported that ultrasonication methods provided shorter reaction times as well as higher $\beta$-lactam yields. ${ }^{21}$ Moreover, it has been demonstrated that the $\beta$ lactam ring is indeed a mechanophore capable of undergoing a mechanically activated cycloelimination reaction. ${ }^{22}$ In the present Note, we computationally analyze how pulling forces acting at the termini of $(E)$-N-ethylpropane-1-imine (abbreviated for simplicity by diethyl-imine in the following) affect the activation and the stereoselectivity of its reaction with two representative ketenes, namely chloro-ketene and CHO-ketene according to Scheme 1, in a classic Staudinger reaction performed in $\mathrm{CH}_{2} \mathrm{Cl}_{2}$ solution. The double bond in the imine reactant is converted into a single bond in the $\beta$-lactam product, which suggests that specific mechanical activation leading to the weakening of 
that particular strong bond in the reactant species could accelerate the reaction. At variance with typical observations in mechanochemical activation of electrocyclic reactions, ${ }^{1920}$ we find that the selectivity of the thermally activated processes is preserved - yet the reactivity of both reactions is greatly enhanced.

Concerning the imine reactant, we have considered only the $E$-diethyl-imine to achieve the largest possible mechanical effect. In the absence of forces, the isolated imine presents nine conformations close in energy (see Figure S1). Among them, two are the most stable ones, aa corresponding to an anti-orientation of the ethyl groups with respect to the central molecular plane, and ab for their eclipsed orientation (see Scheme 2). When constant tensile forces (see Supporting Material for our isotensional EFEI ${ }^{23}$ computational approach and its details) are applied to the terminal methyl groups, the aaanti conformation is found to store the largest amount of mechanical energy for small forces and thus remains more stable than ab-eclipsed up to $0.6 \mathrm{nN}$. For larger forces, abeclipsed and all other conformations except cc also yield a deformed aa-anti conformation as a result of mechanochemical distortion on the force-transformed potential energy surface (see Figure S2).

Scheme 2. Ethyl conformations aa-anti (a) and ab-eclipsed (b) of E-diethyl-imine where the central $\mathrm{N}=\mathrm{C}$ bond is highlighted.

a)

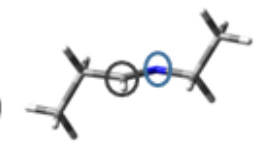

b)

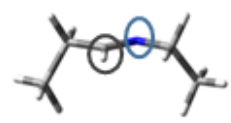

For the Staudinger reactions between diethyl-imine and $\mathrm{Cl} / \mathrm{CHO}$-ketenes and starting with zero external force, we find for both ketenes and for each endo/exo path the two step mechanisms passing through zwitterionic intermediates, $\mathbf{Z}$ (see Figure S3). Upon initial 
contact of the reactants at the transition state TS1, the substituents at C3 and C4 positions slightly favor the exo approach for both ketenes (thus placing both substituents far from the imine). However, in agreement with the torquoelectronic effect, ${ }^{12-24}$ the distinct electronic properties of the two ketene substituents affect the second and rate limiting step via TS2. Thus, the chloro-ketene reaction prefers the exo route by $12 \mathrm{kcal} / \mathrm{mol}$, whereas the CHO-ketene reaction favors the endo one by $0.5 \mathrm{kcal} / \mathrm{mol}$. It has been confirmed that the orientation of ethyl chains in the imine do not exert any influence on the stability of the species involved in these reaction mechanisms in the absence of tensile forces.

With this mechanistic information at hand, tensile forces up to $4.0 \mathrm{nN}$ were applied in increments of $0.1 \mathrm{nN}$ at the C-termini of the imine; all stationary point structures involved in its reaction with $\mathrm{Cl}$ - and $\mathrm{CHO}-\mathrm{ketenes} \mathrm{have} \mathrm{been} \mathrm{optimized} \mathrm{consistently} \mathrm{subject} \mathrm{to} \mathrm{the}$ respective constant forces. As already discussed, the orientation of the ethyl chains in the isolated imine is relevant when forces act on the molecule. To analyze this issue in the Staudinger reaction we have studied all processes when the initial imine reactant has aaanti and ab-eclipsed conformation. The relative Gibbs free energies along the different reaction pathways are calculated with respect to the corresponding isolated reactants subject to the same mechanical force.

We have checked that all TS1 and $\mathbf{Z}$ species respond to the tensile forces in the same way as the isolated imine does (see Figures S4 and S5). That is, at low forces structures with ethyl groups in ab-eclipsed orientation are higher in energy than the corresponding aaanti ones and their ethyl arms tend also to acquire a distorted anti conformation for forces exceeding $0.6 \mathrm{nN}$. Both, TS1 and $\mathbf{Z}$ become stabilized with respect to the respective reactants at forces larger than $0.5 \mathrm{nN}$ in case of both ketenes. In this regime, the TS1 structure is still a first-order saddle point but has a very low imaginary frequency. It has practically the same electronic energy as the respective isolated reactants, thus the Gibbs 
free energy barrier comes from the reduction in entropy caused by the interaction of the two reactants. On the other hand, $\mathbf{Z}$ is more stable than the reactants at every force in terms of electronic energy and undergoes a larger Gibbs free energy stabilization than TS1 as forces increase. However, the activation of the reaction depends on the response of the second transition state TS2, being the rate limiting step, to the applied forces. At TS2, the imine moiety is already bonded to the ketene through N1, so its behavior no more resembles that of the isolated fragment. In fact, two different conformations, aaanti and ab-eclipsed, of endo/exo TS2 structures can be found up to $1.4 \mathrm{nN}$. Figures 1 and 2 depict the Gibbs free activation energy of the four possible reaction pathways, namely endo and exo for both aa-anti and ab-eclipsed,imine ethyl chain conformations in its reaction with Cl-ketene and CHO-ketene, respectively, in the whole range of forces.

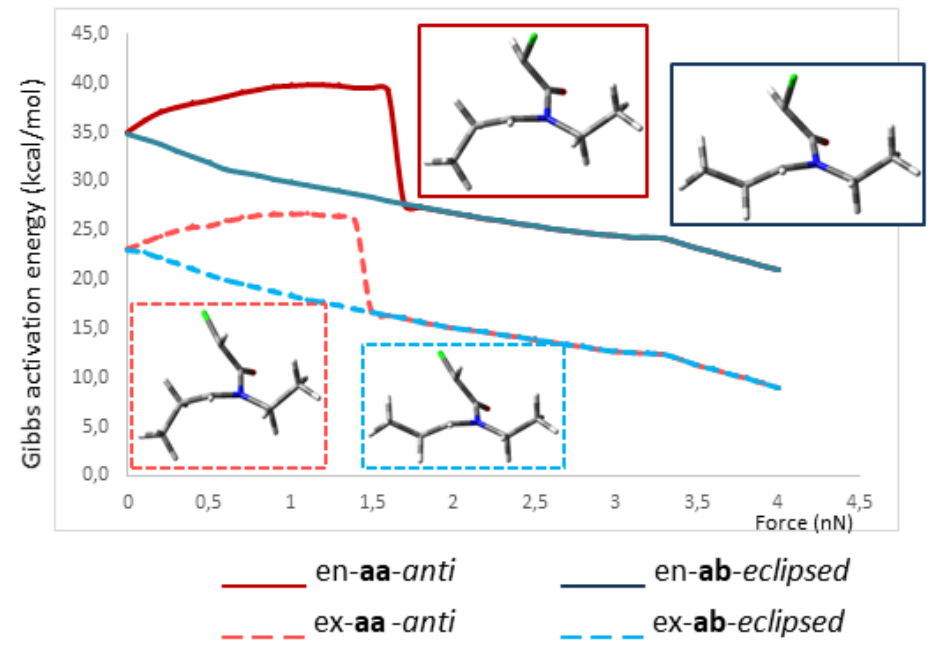

Figure 1. Free activation energy for the endo and exo pathways via aa-anti-TS2 (red) and ab-eclpsed-TS2 (blue) transition states of diethyl-imine and Cl-ketene as a function of increasing forces.

Several key conclusions are disclosed by Figure 1. Firstly, at every force the exo arrangement of the reactants (light color lines) is preferred over the endo one by 
practically the same amount as in the reaction without applying forces, i.e. around 12 $\mathrm{kcal} / \mathrm{mol}$. Importantly, this implies that the application of forces does not affect the torquoselectivity of the process and therefore the chlorine substituent always chooses to place itself outwards in the rate limiting transition state TS2. Secondly, up to $1.4 \mathrm{nN}$, different orientations of the ethyl imine chains respond in different ways to the tensile force. Thus, applying force to the aa-anti conformation (red lines) increases the free energy barrier relative to that at zero force, whereas for ab-eclipsed imine species (blue lines) external forces lead to barriers lower than in the thermal limit. In stark contrast, for forces larger than $1.4 \mathrm{nN}$ a continuous decrease of the activation barrier of the remaining ab-eclipsed conformation, and thus mechanochemically enhanced reactivity, is observed up to the breaking of the imine chain at forces of $3.9 \mathrm{nN}$ or larger (see Supporting Information) while preserving the torquoselectivity of this Staudinger reaction.

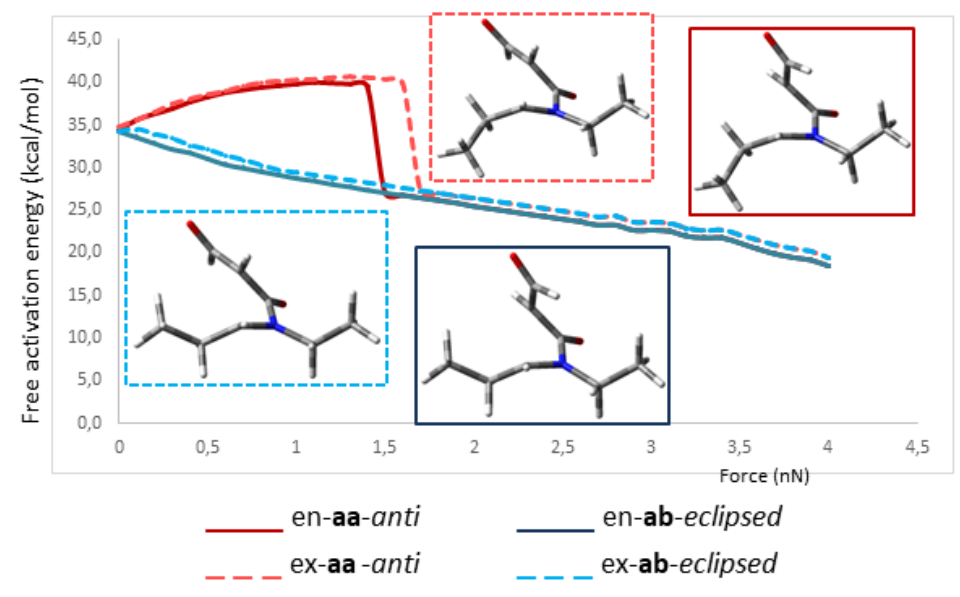

Figure 2. Free activation energy for the endo and exo pathways via aa-anti-TS2 (red) and ab-eclipsed-TS2 (blue) transition states of diethyl-imine and CHO-ketene as a function of increasing forces.

The Staudinger reaction with the CHO-ketene slightly prefers at all forces the endo (dark color lines) over the exo (light color lines) orientation of the reactants by practically the 
same small amount as in the absence of forces, about $0.5 \mathrm{kcal} / \mathrm{mol}$, according to Figure 2. Again, the application of forces does not change the torquoselectivity of the process. The evolution of aa-anti and ab-eclipsed-TS2 structures under increasing forces is analogous to that observed for Cl-ketene. Thus, effective activation of the reaction is clearly achieved.

How can these findings be understood at the molecular level? The reduction in the Gibbs free energy barrier when mechanical tensile forces are applied in the way here described is due to the activation of the imine moiety (see Table S3 for NBO charge analyses of the $\mathrm{N} 1$ and $\mathrm{C} 4$ sites as a function of applied mechanical force). The mechanical coordinate efficiently couples into the N1-C4 bond, thus preparing the molecule for its subsequent bonding to the ketene $\mathrm{C} 2$ and $\mathrm{C} 3$ atoms. Previous studies on the opening of substituted cyclobutadiene have pointed to the formation of a diradical in the corresponding TS. ${ }^{25,26,27}$ An homolytic cleavage of the $\pi$ bond of the imine would lead to a radical at $\mathrm{C} 4$ and could be favored by tensile forces. Concerning torquoselectivity, the orbital or electronic influence of the substituent at $\mathrm{C} 3$ is assumed to affect the shape and relative energy of the frontier molecular orbitals at the rate limiting step. ${ }^{28}$ For our systems we have checked that, on the one hand, the shape of HOMO and LUMO orbitals at TS2 structures does no change when increasing forces are applied (see supporting Figures S6 and S7). On the other hand, the most stable conformation (exo for Cl-ketene and endo for CHO-ketene involving reactions, respectively) yields always the most stable HOMO at TS2 structures (see Figures S6 and S7). Both orbital features clearly support the preservation of the stereochemistry of the products along mechanochemical activation which is known from thermal activation. In fact, the way we have chosen to apply the external forces is crucial to get both, the desired activation while keeping the stereoselectivity of the Staudinger reaction: Tensile forces acting on the imine activate that moiety whereas the ketene 
fragment, where the substituent responsible for torquoselectivity is placed, remains unaltered.

In conclusion, based on the analysis two paradigmatic Staudinger reactions with an electron donating and an electron withdrawing substituent at the ketene, we have demonstrated that the application of tensile forces larger than about $1.4 \mathrm{nN}$ at the terminal C-atoms of the imine results in a significant reduction of the reaction barrier. Such mechanical forces thus activate [2+2] cycloaddition while they preserve the stereochemistry of the final products, that is, mechanochemical activation does not alter the torquoelectronic effect. These findings therefore suggest that imines embedded as mechanophores in polymer chains can be used in sonication experiments to efficiently generate strained four-rings therein with predefined stereochemistry that is governed by the torquoselectivity of the attacking ketene.

\section{COMPUTATIONAL METHODS}

All calculations have been carried out using the Gaussian09 suite of programs $^{29}$ in conjunction with B3LYP/TZVP. ${ }^{30-31}$ The PCM solvent model ${ }^{32}$ has been used to represent the dichloromethane solution; note that computing the activation does not involve charged or zwitterionic species. It has been checked that the inclusion of dispersion interactions ${ }^{33}$ does not affect the reported trends and thus conclusions. The isotensional optimizations ${ }^{34}$ have been performed by applying constant collinear tensile forces (up to $4 \mathrm{nN}$ in increments of $0.1 \mathrm{nN}$ starting with the structures previously optimized at zero applied force) acting on the carbon atoms of the two terminal methyl groups of the diethyl-imine using the EFEI method ${ }^{23}$ as implemented in our in-house modification ${ }^{35}$ of the above-mentioned Gaussian program package (see Supporting Information for further 
details). Recall that applying such highly directional tensile forces at individual molecules as realized in typical sonication setups ${ }^{36,34}$ is distinctly different from applying high hydrostatic pressures to bulk reactive systems.

\section{AUTHOR INFORMATION}

Corresponding Author:

e-mail: isabel@uniovi.es

ORCID:

María Isabel Menéndez: ORCID: 0000-0002-5062-4319

\section{NOTES}

The authors declare no competing financial interest

\section{ACKNOWLEDGMENTS}

We gratefully acknowledge Banco Santander through Campus de Excelencia Internacional of Universidad de Oviedo for having supported the research stay of MIM in Bochum as well as Deutsche Forschungsgemeinschaft (DFG) for partial financial support in the framework of the Koselleck Grant to DM "Understanding Mechanochemistry" (MA/1547-9). 


\section{ASSOCIATED CONTENT}

Supporting Information. The Supporting Information is available free of charge on the ACS Publications website. It contains a more detailed description of the computational methods, the analysis of the diethylimine conformational landscape in the absence of forces and when forces are applied, the Gibbs energy profiles for the Staudinger reactions of diethyl-imine with a) Cl-ketone and b) CHO-ketene in both endo and exo approaches of the reactants in the thermal limit, figures showing the effect of tensile forces on the TS1 and $\mathbf{Z}$ structures, NBO charges for important selected structures as a function of force, the analysis of frontier molecular orbitals of TS2 for the thermally activated reactions and depending on the magnitude of the applied tensile force, and the Cartesian coordinates of some relevant optimized structures.

\section{REFERENCES}

(1) Cho, H.; Uehara, T.; Bernhardt, T. G. Cell 2014, 159 (6), 1300-1311.

(2) Brown, E. D.; Wright, G. D. Nature 2016, 529 (7586), 336-343.

(3) Alcaide, B.; Almendros, P.; Aragoncillo, C. Chemical Reviews. American Chemical Society 2007, pp 4437-4492.

(4) Hevia, E.; Pérez, J.; Riera, V.; Miguel, D.; Campomanes, P.; Menéndez, M. I.; Sordo, T. L.; García-Granda, S. J. Am. Chem. Soc. 2003, 125 (13), 3706-3707.

(5) Pitts, C. R.; Lectka, T. Chem. Rev. 2014, 114 (16), 7930-7953.

(6) Brandi, A.; Cicchi, S.; Cordero, F. M. Chem. Rev. 2008, 108 (9), 3988-4035.

(7) Staudinger, H. Berichte der Dtsch. Chem. Gesellschaft 1907, 40 (1), 1145-1148. 
(8) Palomo, C.; Oiarbide, M. In Beta-Lactams; Springer International Publishing: Cham, 2017; pp 335-372.

(9) Sordo, J. A.; Gonzalez, J.; Sordo, T. L. J. Am. Chem. Soc. 1992, 114 (15), 62496251.

(10) Hutt, A. G.; O’Grady, J. J. Antimicrob. Chemother. 1996, 37 (1), 7-32.

(11) Liang, Y.; Jiao, L.; Zhang, S.; Yu, Z.-X.; Xu, J. J. Am. Chem. Soc. 2009, 131 (4), $1542-1549$.

(12) Kirmse, W.; Rondan, N. G.; Houk, K. N. J. Am. Chem. Soc. 1984, 106 (25), 7989-7991.

(13) Lopez, R.; Sordo, T. L.; Sordo, J. A.; Gonzalez, J. J. Org. Chem. 1993, 58 (25), $7036-7037$.

(14) Liang, Y.; Jiao, L.; Zhang, S.; Xu, J. J. Org. Chem. 2005, 70 (1), 334-337.

(15) Arrieta, A.; Ugalde, J. M.; Cossío, F. P.; Lecea, B. Tetrahedron Lett. 1994, 35 (25), 4465-4468.

(16) Banik, B. K.; Lecea, B.; Arrieta, A.; de Cózar, A.; Cossío, F. P. Angew. Chemie Int. Ed. 2007, 46 (17), 3028-3032.

(17) Linder, M. R.; Podlech, J. Org. Lett. 2001, 3 (12), 1849-1851.

(18) Cossi?o, F. P.; Arrieta, A.; Sierra, M. A. Acc. Chem. Res. 2008, 41 (8), 925-936.

(19) Beyer, M. K.; Clausen-Schaumann, H. Chemical Reviews. American Chemical Society 2005, pp 2921-2948.

(20) Stauch, T.; Dreuw, A. Chem. Rev. 2016, 116 (22), 14137-14180. 
(21) Ramachandra Reddy, P.; Padmaja, A.; Padmavathi, V. J. Heterocycl. Chem. 2015, 52 (5), 1474-1482.

(22) Robb, M. J.; Moore, J. S. J. Am. Chem. Soc. 2015, 137 (34), 10946-10949.

(23) Ribas-Arino, J.; Shiga, M.; Marx, D. Angew. Chemie Int. Ed. 2009, 48 (23), $4190-4193$.

(24) Yasui, M.; Naruse, Y.; Inagaki, S. J. Org. Chem. 2004, 69 (21), 7246-7249.

(25) Morales-Bayuelo, A. Int. J. Quantum Chem. 2013, 113 (10), 1534-1543.

(26) Morales-Bayuelo, A.; Pan, S.; Caballero, J.; Chattaraj, P. K. Phys. Chem. Chem. Phys. 2015, 17 (35), 23104-23111.

(27) Guo, H.; Morales-Bayuelo, A.; Xu, T.; Momen, R.; Wang, L.; Yang, P.; Kirk, S. R.; Jenkins, S. J. Comput. Chem. 2016, 37 (31), 2722-2733.

(28) Murakami, M.; Hasegawa, M. Angew. Chemie Int. Ed. 2004, 43 (37), 4874-4876.

(29) Frisch, M. J.; Trucks, G. W.; Schlegel, H. B.; Scuseria, G. E.; Robb, M. A.; Cheeseman, J. R.; Scalmani, G.; Barone, V.; Mennucci, B.; Petersson, G. A.; Nakatsuji, H.; Caricato, M.; Li, X.; Hratchian, H. P.; Izmaylov, A. F.; Bloino, J.; Zheng, G.; Sonnenberg, J. L.; Hada, M.; Ehara, M.; Toyota, K.; Fukuda, R.; Hasegawa, J.; Ishida, M.; Nakajima, T.; Honda, Y.; Kitao, O.; Nakai, H.; Vreven, T.; Montgomery, J. A.; Peralta, J. E.; Ogliaro, F.; Bearpark, M.; Heyd, J. J.; Brothers, E.; Kudin, K. N.; Staroverov, V. N.; Keith, T.; Kobayashi, R.; Normand, J.; Raghavachari, K.; Rendell, A.; Burant, J. C.; Iyengar, S. S.; Tomasi, J.; Cossi, M.; Rega, N.; Millam, J. M.; Klene, M.; Knox, J. E.; Cross, J. B.; Bakken, V.; Adamo, C.; Jaramillo, J.; Gomperts, R.; Stratmann, R. E.; 
Yazyev, O.; Austin, A. J.; Cammi, R.; Pomelli, C.; Ochterski, J. W.; Martin, R.

L.; Morokuma, K.; Zakrzewski, V. G.; Voth, G. A.; Salvador, P.; Dannenberg, J.

J.; Dapprich, S.; Daniels, A. D.; Farkas, O.; Foresman, J. B.; Ortiz, J. V.;

Cioslowski, J.; Fox, D. J. Gaussian 09, Revision B.01, Gaussian, Inc.,

Wallingford CT. 2009.

(30) Becke, A. D. Phys. Rev. A 1988, 38 (6), 3098-3100.

(31) Schäfer, A.; Huber, C.; Ahlrichs, R. J. Chem. Phys. 1994, 100 (8), 5829-5835.

(32) Scalmani, G.; Frisch, M. J. J. Chem. Phys. 2010, 132 (11), 114110.

(33) Grimme, S.; Antony, J.; Ehrlich, S.; Krieg, H. J. Chem. Phys. 2010, 132 (15), 154104.

(34) Ribas-Arino, J.; Marx, D. Chem. Rev. 2012, 112 (10), 5412-5487.

(35) Krupička, M.; Sander, W.; Marx, D. J. Phys. Chem. Lett. 2014, 5 (5), 905-909.

(36) Caruso, M. M.; Davis, D. A.; Shen, Q.; Odom, S. A.; Sottos, N. R.; White, S. R.; Moore, J. S. Chem. Rev. 2009, 109 (11), 5755-5798. 